\title{
Disseminated Nocardia farcinica infection in a patient with myasthenia gravis successfully treated by linezolid: a case report and literature review.
}

\section{$\operatorname{AUTHOR}(S)$ :}

Tanioka, Kosuke; Nagao, Miki; Yamamoto, Masaki; Matsumura, Yasufumi; Tabu, Hayato; Matsushima, Aki; Uemura, Kengo; ... Takakura, Shunji; Takahashi, Ryosuke; Ichiyama, Satoshi

\section{CITATION:}

Tanioka, Kosuke ... [et al]. Disseminated Nocardia farcinica infection in a patient with myasthenia gravis successfully treated by linezolid: a case report and literature review.. Journal of infection and chemotherapy: official journal of the Japan Society of Chemotherapy 2012, 18(3): 390-394

\section{ISSUE DATE:}

2012-06

\section{URL:}

http://hdl.handle.net/2433/160126

\section{RIGHT:}

The final publication is available at www.springerlink.com; この論文は 出版社版でありません。引用の際には出版社版をご確認ご利用くださ $\iota_{\circ} ;$ This is not the published version. Please cite only the published version. 
1 Disseminated Nocardia farcinica infection in a patient with

2 myasthenia gravis successfully treated by linezolid. a case report

3 and literature review

4

5 Kosuke Tanioka ${ }^{1}$, Miki Nagao ${ }^{2,3}$, Masaki Yamamoto ${ }^{2,3}$, Yasufumi

6 Matsumura ${ }^{2,3}$, Hayato Tabu ${ }^{1}$, Aki Matsushima ${ }^{2,3}$, Kengo Uemura ${ }^{1}$, Riki

7 Matsumoto ${ }^{1}$, Yutaka Ito $^{2,4}$, Shunji Takakura ${ }^{2,3}$, Ryosuke Takahashi ${ }^{1}$, Satoshi

$8 \quad$ Ichiyama ${ }^{2,3}$

9

$10{ }^{1}$ Department of Neurology, Kyoto University Graduate School of Medicine

112 Department of Infection Control and Prevention, Kyoto University

12 Hospital,

$13{ }^{3}$ Department of Clinical Laboratory Medicine, Kyoto University Graduate

14 School of Medicine,

$15{ }^{4}$ Department of Respiratory Medicine, Kyoto University Graduate School of

16 Medicine

17 Shogoin Kawahara-cho 54, Sakyo-ku, Kyoto Japan 
19 Key words : Invasive nocardiosis, Linezolid, Nocardia farcinica

21 Corresponding author

22 Miki Nagao, Department of Infection Control and Prevention,

23 Kyoto University Hospital

24 Shogoin Kawahara-cho 54 , Sakyo-ku, Kyoto, Japan

25 Postal code 606-8507

$26 \quad$ Tel \& Fax +81757514967

$27 \quad$ Email: mnagao@kuhp.kyoto-u.ac.jp

28

29 
$30 \quad$ Abstract

31 Nocardiosis is increasingly being diagnosed due to a growing population of

32 immunocompromised hosts and improvements in the detection of Nocardia species in clinical laboratories. Historically, sulphonamides have been the

34 first-line therapy for the treatment of nocardiosis, but sulphonamides tend to

35 have high rate of drug allergy in clinical settings. In this report, we

36 described a disseminated $N$. farcinica infection occurred in a patient with

37 myasthenia gravis, who suffered from multiple drug allergies and was

38 successfully treated using linezolid. We undertook a review of literature of

39 previously reported cases of nocardiosis treated with linezolid. To date, only

$40 \quad 15$ cases of nocardiosis treated with linezolid have been published. All cases

41 exhibited long-term tolerance of linezolid and 14 out of 15 cases showed

42 either an improvement in or complete clearance of the infection. According

43 to the literature review, linezolid is an attractive alternative to

44 trimethoprim-sulfamethoxazole for the treatment of disseminated nocardiosis, despite limited clinical evidence to support this claim. 
48 Nocardiosis is increasingly being diagnosed due to a growing population of

49 immunocompromised hosts and improvements in the detection and

50 identification of Nocardia species in clinical laboratories. However, none of

51 the reported cases have been diagnosed concomitantly with myasthenia

52 gravis $(\mathrm{MG})$, making this the first reported case of its kind. Data regarding

53 prognosis in nocardiosis are highly variable, with published mortality rates

54 ranging from $14 \%$ to $40 \%$ [1-3]. In cases of disseminated infection, mortality

55 rates may even approach $100 \%$.

56 In this report, we describe a disseminated infection (with bacteraemia,

57 multilobar pneumonia, and kidney and brain abscesses) caused by $\mathrm{N}$.

58 farcinica that occurred in a patient with MG. This patient suffered from

59 multiple drug allergies and was successfully treated using linezolid. In

60 addition reported cases of nocardiosis treated with linezolid were reviewed.

61

62 Case report

63 A 59-year-old woman was admitted to Kyoto University Hospital with

64 malaise, cough and stomatitis in October 2010. She had been diagnosed 
65 with myasthenia gravis (MG) one year prior to admission and had received immunosuppressive treatment, including prednisolone ( $15 \mathrm{mg}$ once daily ) and tacrolimus. Upon admission, she appeared acutely ill and complained a shortness of breath with body movement. Physical examination revealed a body temperature of $36.5{ }^{\circ} \mathrm{C}$, a respiratory rate of 24 breaths per minute, blood pressure of $71 / 52 \mathrm{~mm} \mathrm{Hg}$, and a heart rate of 106 beats per minute. Diffuse crackles were audible in both upper lungs. Laboratory tests revealed hemoglobin of $8.0 \mathrm{mg} / \mathrm{dL}$, a white blood cell count of $19,100 / \mathrm{mm}^{3}$, platelet count of $465 \times 10^{9} / \mathrm{L}$, total protein of $4.4 \mathrm{~g} / \mathrm{dL}$, albumin of $2.4 \mathrm{~g} / \mathrm{dL}$, C-reactive protein of $10.9 \mathrm{mg} / \mathrm{dL}$, and IgG of $363 \mathrm{mg} / \mathrm{dL}$. Chest radiographs and computed tomography (CT) scanning showed extensive diffuse bilateral reticulonodular infiltrates. An abdominal CT showed an abscess in the right kidney, whereas a head CT did not reveal any abnormalities. Neither vegetation nor valvular thickening was detected during transthoracic echocardiography, which ruled out infective endocarditis. Two sets of blood

80 cultures and a sputum culture were obtained, and piperacillin-tazobactam (TZP) 4.5g q8h and ciprofloxacin (CIP) 300mg q12h were started based on a presumptive diagnosis of severe healthcare-associated, community-acquired 
83 pneumonia and pyogenic kidney abscesses. Gram staining of the sputum

84 showed Gram-positive filaments suggestive of Nocardia spp. or Actinomyces.

85 TZP and CIP were changed to imipenem-cilastatin (IPM) $0.5 \mathrm{~g} q 6 \mathrm{~h}$ and

86 trimethoprim-sulphamethoxazole (TMP) 4 tablets orally q12h on the fourth

87 day, due to a deterioration in respiratory function. On the seventh day, the

blood and sputum cultures collected at admission grew a "Corynebacterium

“ species, based on identification using a VITEK 2 system (bioMérieux,

Marcy l'Etoile, France). This culture was further identified as $N$. farcinica via sequencing analysis of the $16 \mathrm{~S}$ rRNA gene of the isolates and the phenotype of the bacteria. The isolate was susceptible to cefotaxime $(<=$ $\left.2.0 \mathrm{ug} \mathrm{ml} l^{-1}\right), \operatorname{AMK}\left(<1.0 \mathrm{ug} \mathrm{ml}^{-1}\right), \operatorname{CPFX}\left(1.0 \mathrm{ug} \mathrm{ml}^{-1}\right), \operatorname{IPM}\left(<=0.5 \mathrm{ug} \mathrm{ml}^{-1}\right)$, minocycline (MINO) (1.0 ug ml-1), and resistant to gentamicin $\left(32 \mathrm{ug} \mathrm{ml}^{-1}\right)$, TZP ( $128.0 \mathrm{ug} \mathrm{ml}^{-1}$ ). We changed IPM and TMP to MINO on the eighteenth day due to a generalised skin rash and a facial flushing that seemed to be caused by a drug allergy. Accordingly, we attempted desensitisation to TMP.

98 Cyclosporine was started on the thirty-sixth day as a treatment for MG, as the physical signs of systemic illness were gradually improving.

100 On the fifty-seventh day, the patient's fever rose to $38^{\circ} \mathrm{C}$. She was free of 
101 neurological symptoms, but multiple brain abscesses were detected by

102 magnetic resonance imaging, and an abdominal CT showed enlargement of

103 the abscess on the right kidney. We tried meropenem and amikacin, but

104 infectious symptoms were not improved. Linezolid 600mg q12h was started,

105 with subsequent improvement in the brain and right kidney abscesses.

106 Mild thrombocytopenia developed on the ninety-seventh day (the platelet

107 count decreased from $465 \times 10^{9} / \mathrm{L}$ to $121 \times 10^{9} / \mathrm{L}$ ), and linezolid therapy was

108 changed to TMP. Any side effect other than mild thrombocytopenia did not

109 occur during 38-day course of linezolid therapy. The patient was discharged

110 on the one hundred twentieth day and was followed up at an outpatient

111 clinic without a worsening of infectious symptoms or a severe adverse

112 reaction to TMP.

114 Disucussion

115 We reported herein a case of disseminated $N$. farcinica infection in which the

116 causative organism was misidentified as a Corynebacterium spp. and a drug

117 allergy to the first-line therapy for nocardiosis altered antibiotic selection.

118 Nocardia spp. can be cultured on most bacterial media, and thus a high 
119 degree of suspicion is needed for diagnosis of nocardiosis. This includes

120 consideration of the patient's underlying illnesses and unique bacterial

121 characteristics identified via Gram and Ziehl-Neelsen staining. In the early

122 phase of growth on standard media, the organisms may resemble

123 'diphtheroid' bacilli, which commonly contaminate samples. This may lead

124 to an incorrect identification of patient cultures. In the case presented here,

125 an automatic identification system misidentified the bacilli as

126 Corynebacterium spp.; however, actinomycosis was strongly suspected due to

127 the patient's background and clinical progression. Therefore, we performed

128 sequencing analysis of the $16 \mathrm{~S}$ rRNA gene of the isolates and made a

129 confirmatory diagnosis using the biological characteristics of the cultured

130 bacteria. Culture contaminants are commonplace, and invasive Nocardia

131 infections are rare. Therefore, close collaboration between clinicians and

132 clinical laboratories is necessary for the optimal diagnosis and treatment of

133 patients.

134 Historically, sulphonamides have been the first-line therapy for the

135 treatment of nocardiosis, with TMP being the most commonly used

136 treatment. Sulpha drugs may reduce the mortality rate when used alone or 
137 in combination with other antimicrobials [1,2]. In an immunocompromised

138 patient with severe, progressive infection or central nerve system

139 involvement, treatment should involve a combined therapy of either TMP

140 and a bactericidal agent or a combination of imipenem and amikacin [1-3].

141 In the current case, we decided to treat with amikacin (with close monitoring

142 of neurological status) and IPM despite the patient's diagnosis of MG, due to

143 the emergence of a drug allergy to TMP. Unfortunately, an allergic reaction

144 to IPM also occurred, and the renal abscess worsened; therefore, we

145 administered linezolid as a last line of defence.

146 Linezolid crosses the blood-brain barrier and has excellent bioavailability.

147 In vitro activity of linezolid against Nocardia spp. was observed in several

148 studies. Brown-Elliott et al. tested 140 clinical isolates by broth

149 microdilution and demonstrated that linezolid concentrations of $4 \mathrm{ug} / \mathrm{mL}$

150 inhibited $90 \%$ isolates (90\% minimum inhibitory concentration), which is in

151 susceptible range according to the proposed Clinical and Laboratory

152 Standard Institute MIC breakpoint. [4] In another study testing 93

153 Nocardia isolates by the Etest method, all isolates were susceptible to

154 linezolid. [5] Thus, it is an attractive alternative treatment for central 
155 nervous system nocardiosis, despite limited clinical evidence to support this

156 claim.

157 Fifteen cases of nocardiosis treated with linezolid have been published to

158 date.(Table)[6-15] Linezolid has a well-documented short-term adverse

159 effect profile, with headache and diarrhoea most commonly seen; however,

160 its long-term safety profile (>28 days) has not been extensively studied. In

1619 of these cases, linezolid was selected due to a lack of tolerance to TMP or

162 beta-lactams, and 2 cases were due to multidrug resistant Nocardia spp.

163 All cases exhibited long-term tolerance of linezolid (median 120; range

164 30-720 days) and 14 out of 15 cases showed either an improvement in or

165 complete clearance of the infection. Whether linezolid treatment is superior

166 to TMP or beta-lactam treatment is still unknown; however, this agent may

167 be a last resort for nocardiosis. Information on efficacy and outcomes

168 similar to this report will be important in treating Nocardia spp. infections,

169 due to the need for an extended course of treatment and the relative lack of

170 available data.

171 Although reviews of therapy for Nocardia infections recommend TMP as the

172 therapeutic drug of choice, sulphonamide-resistant Nocardia infections have 
173 been reported in many countries, including the United States, Japan, France

174 and Britain[16,17]. TMP susceptibility varies geographically, and TMP

175 resistance ranges from a low of $32 \%$ for $N$. brevicatena to $93 \%$ for $N$.

176 farcinica. Multidrug resistance may also occur with $N$. farcinica, and thus

177 susceptibility varies among Nocardia species as well. In addition, Tremblay

178 et al. recently reported the high frequency of isolation of $N$. farcinica from

179 specimens that indicated invasive disease (such as brain or lung biopsies and

180 blood) [16]. Given the preponderance of invasive $N$. farcinica infection and

181 the frequent non- susceptibility of isolates to TMP, this drug may no longer

182 be the first choice in some regions.

183 Publication bias is an important consideration, as some authors hesitate to

184 publish or present cases with poor outcomes. Another limitation is that the

185 published evidence regarding the efficacy and safety of linezolid in patients

186 with nocardiosis is derived solely from a small subset of case reports.

187 Although the incidence of nocardiosis is thought to be on the rise, it remains

188 a rare opportunistic infection. Thus, it is difficult to establish the use of

189 linezolid in the therapeutic regimen for nocardiosis through randomised

190 controlled trials. 
191 Additional accumulation of case reports regarding the use of linezolid in

192 Nocardia infections will be of use to clinicians and patients suffering from

193 disseminated nocardiosis.

194

195 Acknowledgement:

196 We would like to thank Professor Tohru Gonoi at Medical Mycology Research

197 Center, Chiba University for performing biological tests for Nocardia

198 indentification.

199

200 Funding: None

201 Ethical approval: Not required

202 Conflict of interest: No conflict of interest to declare

203

204

205

206

207

208

209

210 


\section{Reference}

213

214 1. Sonnell TC, Mitchell DH, Iredell JR. Nocardia species. In: Mandell GL,

215 Bebbett JE, Dolin R, eds. Principles and practice of infectious diseases. 7th

216 ed. New York: Elsevier, 2010:3199-3207

217

218 2. Brown-Elliott BA, Brown JM, Conville PS, Wallace RJ Jr. Clinical and 219 laboratory features of the Nocardia spp. based on current molecular taxonomy. Clin Microbiol Rev 2006; 19:259-82.

221

222

3. Ambrosioni J, Lew D, Ganbino J. Nocardiosis: updated clinical review and experience at a tertiary center. Infection 2010;38:89-97

224

225

4. Brown-Elliot BA, Ward SC, Crist CJ, Mann LB, Wilson RW, Wallace RJ Jr. In vitro activities of linezolid against multiple Nocardia species.

Antimicrob Agents Chemother 2001;45:1295-7.

228

5. Glupczynski Y, Berhin C, Janssens M, Wauters G. Determination of antimicrobial susceptibility patterns of Nocardia spp. from clinical specimens by Etest. Clin Microbiol Infect 2006;12:905-12.

232

6. Lewis KE, Ebden P, Wooster SL Rees J, Harrison GA. Multi-system 
234 infection with Nocardia farcinica therapy with linezolid and minocycline. J

235 Infect 2003; 46:199-202.

236

237

7. Moitra RK, Auckland C, Cawley M, Jones G, Cooper C. Systemic nocardiosis in a splenectomized patient with systemic lupus erythematosus: successful treatment using linezolid. J Clin Rheumatol 2003;9:47-50.

8. Moylett EH, Pacheco SE, Brown-Elliott BA, Perry TR, Buescher ES,

Birmingham MC et al. Clinical experience with linezolid for the treatment of

Nocardia infection. Clin Infect Dis 2003; 36: 313-8.

9. Rupprecht TA, Prister HW. Clinical experience with linezolid for the treatment of central nervous system infections. Eur J Neurol 2005;12:536-42.

10. Vigano SM, Edefonti A, Ferraresso M, Ranzi ML, GrossiP, Righini A et al.

Successful medical treatment of multiple abscesses due to Nocardia farcinica in pediatric renal transplant recipient. Pediatr Nephrol 2005;20:1186-8.

254 abscesses in a male patient with SLE: successful outcome despite delay in diagnosis. Clin Rheumatol 2007;26:1020-2. 
257

258

259

260

261

262

263

264

265

266

267

268

269

270

271

272

273

274

275

276

277

278

279

12. Rivero A, Garcia-Lazaro M, Perez-Camacho I, Natera C, del Carmen

Almodovar M et al. Successful long-term treatment with linezolid for

disseminated infection with multiresistant Nocardia farcinica. Infection 2008;36: 389-91.

13. Falcone M, Pompeo ME, Fabi F, Venditti M. Linezolid therapy for the treatment of nocardia infection: report of a case and review of the literature.

Le infezioni in Medicina 2008;2:94-98

\section{Al-Tawfiq JA, Al-Khatti AA. Disseminated systemic Nocardia farcinica} infection complicating alefacept and infliximab therapy in a patient with severe psoriasis. Int J Infect Dis. 2010 Feb;14(2):e153-7

15. Shen Q, Zhou H, Li H, Zhou J. Linezolid combined with trimethoprim-sulfamethoxazole therapy for the treatment of disseminated nocardiosis. J Med Microbiol. $2011 ; 7$ :1043-5.

\section{Tremblay J, Thibert L, Alarie I, Valiquette L, Pe'pin J. Nocardiosis in}

Quebec, Canada, 1988- 2008. Clin Microbiol Infect 2010. July 15 epub

17. Uhde KB, Pathak S, McCullum I Jr., Jannat-Khah DP, Shadomy SV, Dykewicz CA et al. Antimicrobial-resistant Nocardia isolates, United States, 1995-2004. Clin Infect Dis 2010;51:1445-8 
Table Summary of cases of linezolid use for nocardiosis

\begin{tabular}{|c|c|c|c|c|c|c|c|c|c|}
\hline No. & $\begin{array}{l}\text { Age } \\
(y) \\
\text { Sex }\end{array}$ & Co-morbidities & Infection Site & Nocardia spp. & Indication & Outcome & Linezolid ADRs & $\begin{array}{l}\text { Duration of } \\
\text { Linezolid } \\
\text { use (days) }\end{array}$ & Reference \\
\hline 1 & $\mathrm{NA} / \mathrm{M}$ & Trauma & Disseminated & N. farcinica & $\mathrm{ADRs}_{\mathrm{s}}$ & $\begin{array}{l}\text { Cure (followed } \\
\text { by minocycline) }\end{array}$ & $\begin{array}{c}\text { Myelosuppression, } \\
\text { optic neuritis }\end{array}$ & 150 & [6] \\
\hline 2 & $29 / \mathrm{F}$ & SLE & Disseminated & N. asteroides & $\mathrm{ADRs}$ & $\begin{array}{c}\text { Cure (followed } \\
\text { by IPM and } \\
\text { AMK) }\end{array}$ & $\begin{array}{l}\text { Peripheral } \\
\text { neuropathy }\end{array}$ & 120 & [7] \\
\hline 3 & $45 / \mathrm{M}$ & Silicosis/steroid & Disseminated & $N$. asteroides & $\mathrm{ADRs}$ & Cure & None & 365 & \\
\hline 4 & $63 / \mathrm{M}$ & Silicosis/steroid & Disseminated & NA & $\begin{array}{l}\text { Sulphona- } \\
\text { mide } \\
\text { allergy }\end{array}$ & Cure & Anemia & 90 & [8] \\
\hline 5 & $54 / \mathrm{F}$ & None & Facial cellulitis & NA & $\begin{array}{l}\text { Clinical } \\
\text { failure }\end{array}$ & $\begin{array}{l}\text { Cure (followed } \\
\text { by TMP) }\end{array}$ & Anemia & 60 & \\
\hline
\end{tabular}




\begin{tabular}{|c|c|c|c|c|c|c|c|c|c|}
\hline & & & & & & & & \\
\hline 6 & $52 / \mathrm{F}$ & None & Disseminated & $\begin{array}{l}\text { N. otitidisca- } \\
\text { varium }\end{array}$ & $\mathrm{ADRs}_{\mathrm{s}}$ & Cure & $\begin{array}{c}\text { Anemia, } \\
\text { thrombocytopenia, } \\
\text { lactic acidosis, } \\
\text { peripheral } \\
\text { neuropathy }\end{array}$ & 120 & \\
\hline 7 & $6 / \mathrm{M}$ & CGD & Lung & $N$. asteroides & $\begin{array}{l}\text { Clinical } \\
\text { failure }\end{array}$ & Cure & None & 790 & \\
\hline 8 & $9 / \mathrm{M}$ & CGD & Disseminated & $\mathrm{NA}$ & $\mathrm{ADRs}$ & Cure & None & 365 & \\
\hline 9 & $58 / \mathrm{M}$ & NA/steroid & Brain abscesses & N. farcinica & NA & $\begin{array}{l}\text { Improvement } \\
\text { (followed by } \\
\text { meropenem and } \\
\text { amoxicillin/clav } \\
\text { ulanate) }\end{array}$ & None & 49 & {$[9]$} \\
\hline 10 & $12 / \mathrm{M}$ & $\begin{array}{c}\text { Kidney } \\
\text { transplant }\end{array}$ & Brain abscesses & N. farcinica & $\begin{array}{l}\text { Clinical } \\
\text { failure }\end{array}$ & Cure & Anemia & 60 & [10] \\
\hline 11 & $37 / \mathrm{M}$ & SLE & Brain abscesses & N. asteroides & $\begin{array}{c}\text { Adjunctive } \\
\text { therapy }\end{array}$ & Improvement & NA & NA & [11] \\
\hline 12 & $42 / \mathrm{F}$ & Heart transplant & Brain abscesses & N. farcinica & $\begin{array}{l}\text { Multidrug } \\
\text { resistance }\end{array}$ & Cure & $\begin{array}{l}\text { Mild sensory } \\
\text { neuropathy }\end{array}$ & 510 & [12] \\
\hline
\end{tabular}




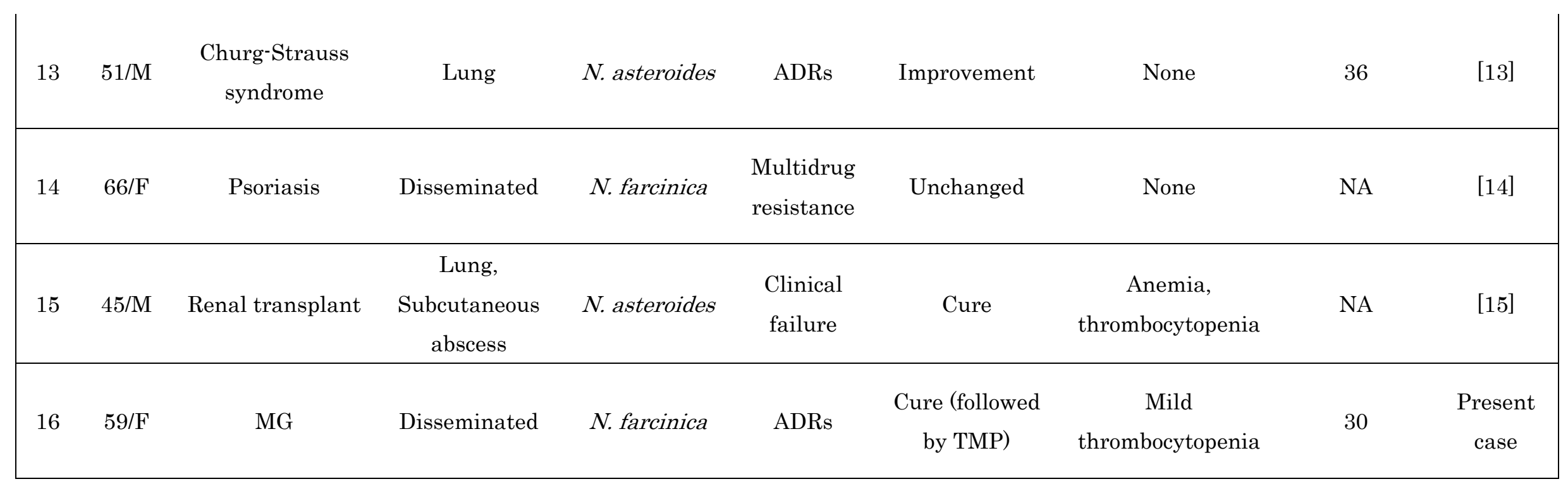

$\mathrm{NA}=$ not available; $\mathrm{ADR}=$ adverse drug reaction; $\mathrm{SLE}=$ systemic lupus erythemtatotes $\mathrm{CGD}=$ chronic granumatous disease $; \mathrm{MG}=$ myasthenia gravis 